\title{
Back-analysis of PC1 cave propagation and subsidence behaviour at the Cadia East mine
}

\author{
B Sainsbury Noma Consulting and Deakin University, Australia \\ D Sainsbury Noma Consulting, Australia \\ D Carroll Newcrest Mining Limited, Australia
}

\begin{abstract}
Based on the successful initiation and breakthrough to surface of the PC1 cave at Cadia East, a back-analysis of the performance was conducted to confirm design parameters to optimise the future draw strategy. A mine-scale numerical model was developed to calibrate the existing caving and subsidence behaviour associated with the initiation of PC1 and development of the crater. The successful calibration of historical conditions has provided significant confidence in the caving and subsidence predictions associated with future draw strategies. It has also validated a methodology to simulate the effects of preconditioning in large-scale models.
\end{abstract}

Keywords: caving, subsidence, PC1, Cadia East, numerical modelling, preconditioning

\section{$1 \quad$ Background}

Cadia Valley Operations (CVO) is one of Australia's largest gold mining operations and is $100 \%$ owned by Newcrest. It is located approximately $25 \mathrm{~km}$ from the city of Orange in central west New South Wales and is $250 \mathrm{~km}$ west of Sydney. Cadia Valley Operations comprises three mines - the Ridgeway sublevel cave and Ridgeway Deeps (currently on care and maintenance), the Cadia Hill open pit (currently on care and maintenance) and the Cadia East panel cave. Cadia East commenced commercial production on 1 January 2013 from Panel Cave 1 (PC1).

Based on the successful initiation of the PC1 cave and its breakthrough to surface, a back-analysis of the propagation performance has been conducted to confirm geomechanical design parameters for the optimisation of the future draw strategy and understanding the impact that preconditioning had on the rock mass strength and subsequent propagation behaviour.

Based on observations made during cave propagation, a total of five significant events were established for PC1. The historical conditions were established based on monitoring data that included open holes, visual observations and seismic data. They are summarised below.

1. A hydraulic fracturing program was conducted immediately above the PC1 footprint $(4,670 \mathrm{~m} \mathrm{RL})$ up to $5,050 \mathrm{~m}$ RL. Cave initiation occurred with an initial propagation rate of $3-4.5 \mathrm{~m} /$ day. This propagation rate continued up to the $5,050 \mathrm{~m}$ RL Level ( $260 \mathrm{~m}$ cave height) and continued up to the $5,250 \mathrm{~m}$ RL Level with few problems. As the cave passed the 5,250 m RL Level, observations showed that the crown of the cave was beginning to narrow (or neck).

2. During early 2014 , the cave back (now $750 \mathrm{~m}$ in height) reached a strong and competent rock mass (upper capping porphyry) that is located at 5,470 m RL; approximately $450 \mathrm{~m}$ below the ground surface. As the cave back reached this unit, caving slowed, and a stable arch was formed.

3. The mobilised zone from PC1 intersected the 5,050 m RL Level prior to the end of Q1 2014. 
4. Due to the cave stalling on the capping porphyry, an intensive hydraulic fracturing program was conducted from the surface to $450 \mathrm{~m}$ depth. During October 2014, cave propagation commenced again at a rate of $10 \mathrm{~m} /$ day (rapid).

5. Surface breakthrough occurred on 22 October 2014.

Each geotechnical observation provides a chronology of the cave performance and provides validation points for geomechanical performance modelling.

\section{Introduction}

This paper provides a detailed description of the geomechanical parameters used to re-create the historical conditions during the PC1 propagation and surface breakthrough. The back-analysis was completed based on a numerical modelling technique that has been developed and validated over several years based on case study applications. A full description of the modelling technique can be found in Sainsbury (2012).

Documented case studies include:

- Northparkes E26 Lift 2 (Pierce et. al. 2007).

- Palabora mine (Sainsbury et. al. 2008; Sainsbury et al. 2016).

- Grace Mine (Sainsbury et. al. 2010).

- Henderson Mine (Sainsbury et. al. 2011).

- Kiirunavaara Lake Orebody (Sainsbury \& Stöckel 2012).

The modelling methodology simulates the evolving rock mass damage around a propagating cave as a result of a specified draw strategy, evolving induced stress conditions and the simulated constitutive behaviour of the rock mass. Through this technique, each of the cave and subsidence behavioural regions can be interpreted based on displacement and strain criteria. The conceptual model of a propagating cave and its surface subsidence expression is presented in Figure 1.

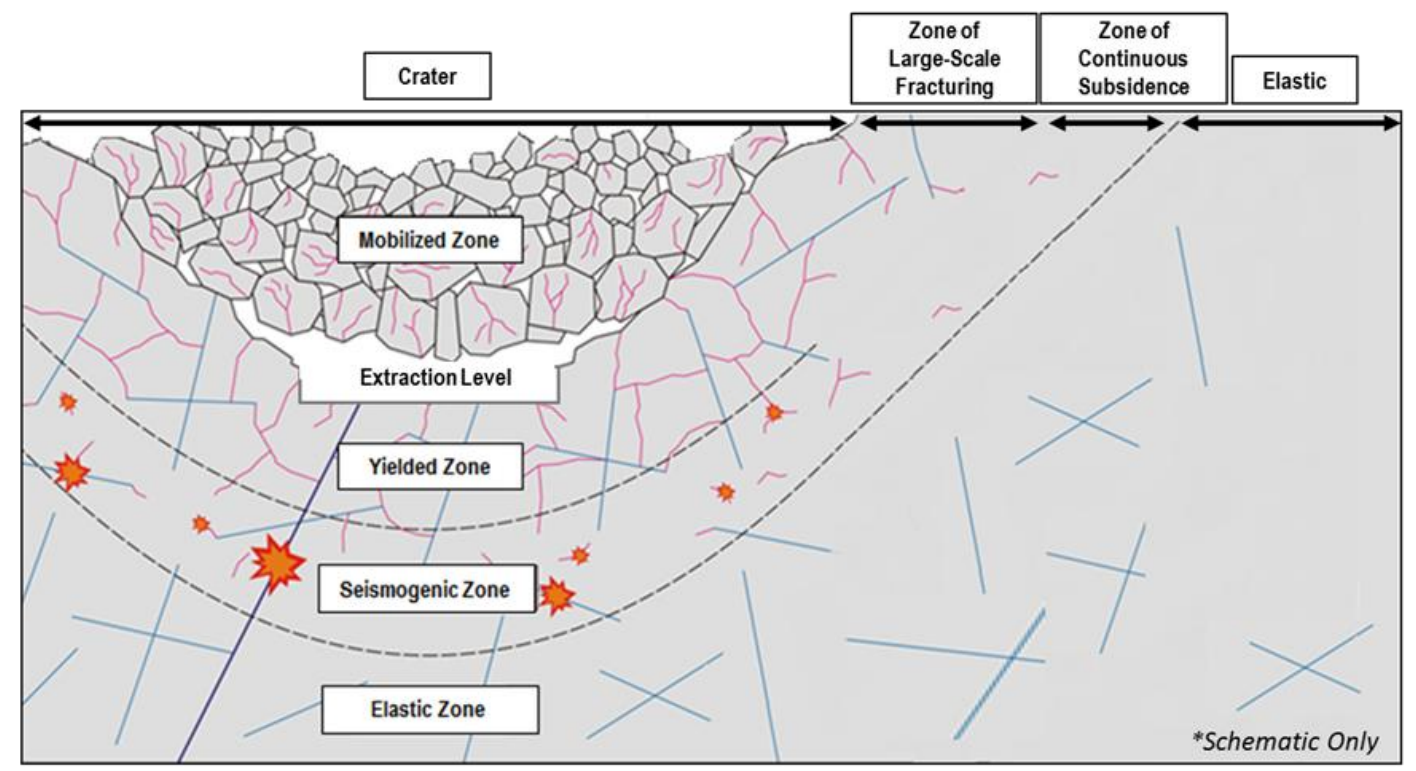

Figure 1 Behavioural regions of a propagation cave (modified after Sainsbury 2012)

\subsection{Yielded zone/zone of large-scale fracturing}

The rock mass in this region is fractured and has lost some or all of its cohesive strength and provides minimal support to the overlying rock mass. A rock mass within the yielded zone is subject to significant damage, i.e. open holes are cut off, time domain reflectometry (TDR) breakages are expected and cracking is observable 
in infrastructure. Stress components within this region are typically low in magnitude. The reduction in rock block size (compared to the in situ state) due to yielding in this region can be described as primary fragmentation. Primary fragmentation from a stress caving mechanism is generally finer than that from gravity caving (Laubscher 1994).

The ground surface within this zone is broken and has large open tension cracks, benches, and rotational blocks. Usually, the primary failure mechanism of surface cracks associated with cave mines is shear failure of the abutment rock mass, which results in the development of stepped benches and scarps. Other types of failure mechanisms, such as toppling and block rotation, are also present, but they appear to be secondary mechanisms that form after the primary shear failure develops. A total strain criterion of $0.5 \%$ has previously been used by Sainsbury and Lorig (2005) to calibrate the limits of large-scale fracturing at the abandoned Grace Mine in Pennsylvania, USA. This total strain criterion has also been used to calibrate the limit of large-scale fracturing at the El Teniente block cave mine in Chile (Cavieres et al. 2003).

\subsection{Mobilised zone/crater}

This zone gives an estimate of the portion of the orebody that has moved in response to the production draw and may be recoverable. Although the specific location of the cave back is difficult to predict precisely, it is estimated to be rock that has experienced a displacement greater than or equal to $2 \mathrm{~m}$. The reduction in rock block size (compared to the primary fragmentation state) is described as secondary fragmentation. Secondary fragmentation is affected by draw height and internal caving stresses (Laubscher 1994).

A crater is the surface expression of the mobilised zone. It is also referred to as the zone of active movement (van As et al. 2003). The crater consists of irregular blocks of rock, ranging in size from millimetres to several metres in magnitude. It develops as the mobilised zone influence reaches the ground surface, causing the overlying rock mass and/or side rock to fall into the mined void. Over time, the surface of the crater may subside as ore is withdrawn (Lupo 1998).

\section{Geomechanical parameters}

Geomechanical parameters have been developed based on measurable rock mass parameters that have been recorded at the site. By prescribing the input strength and stiffness parameters, a realistic representation of the deformation modulus, unconfined compressive strength (UCS), tensile strength and the softening behaviour for each domain through different stress paths can be completed. This technique allows accurate failure mechanisms to be honoured during the various progression stages of the cave.

\subsection{In situ stresses}

The stresses outlined in Table 1 were used to define the pre-mining stress conditions within the model. They have been derived based on a review of stress measurement data completed by Lee (2012).

Table 1 In situ stress regime (after Lee 2012)

\begin{tabular}{llll}
\hline & Magnitude (MPa) & Dip ( $\left(^{\circ}\right)$ & Dip direction ( $\left(^{\circ}\right)$ \\
\hline$\sigma_{1}$ & $5+0.0479 \times$ depth & 0 & 074 \\
$\sigma_{2}$ & $0+0.0344 \times$ depth & 0 & 164 \\
$\sigma_{3}$ & $0+0.0297 \times$ depth & 90 & 074 \\
\hline
\end{tabular}

\subsection{Peak rock mass properties}

A bilinear Mohr-Coulomb strain-softening constitutive model has been used to simulate the complex process of the progressive failure and disintegration of the rock mass from an in situ to bulked rock mass state within and around the cave column. 
The Mohr-Coulomb criterion has been used to define the peak strength of each of the rock mass domains through a least squares fit to the Hoek-Brown envelope developed from the measured Geological Strength Index (GSI), $\sigma_{\mathrm{ci}}$ and $m_{i}$ values. A geological section through PC1 cave column is presented in Figure 2 . For reference, the PC1 footprint dimension is $350 \mathrm{~m}$ in the east-west direction (shown).

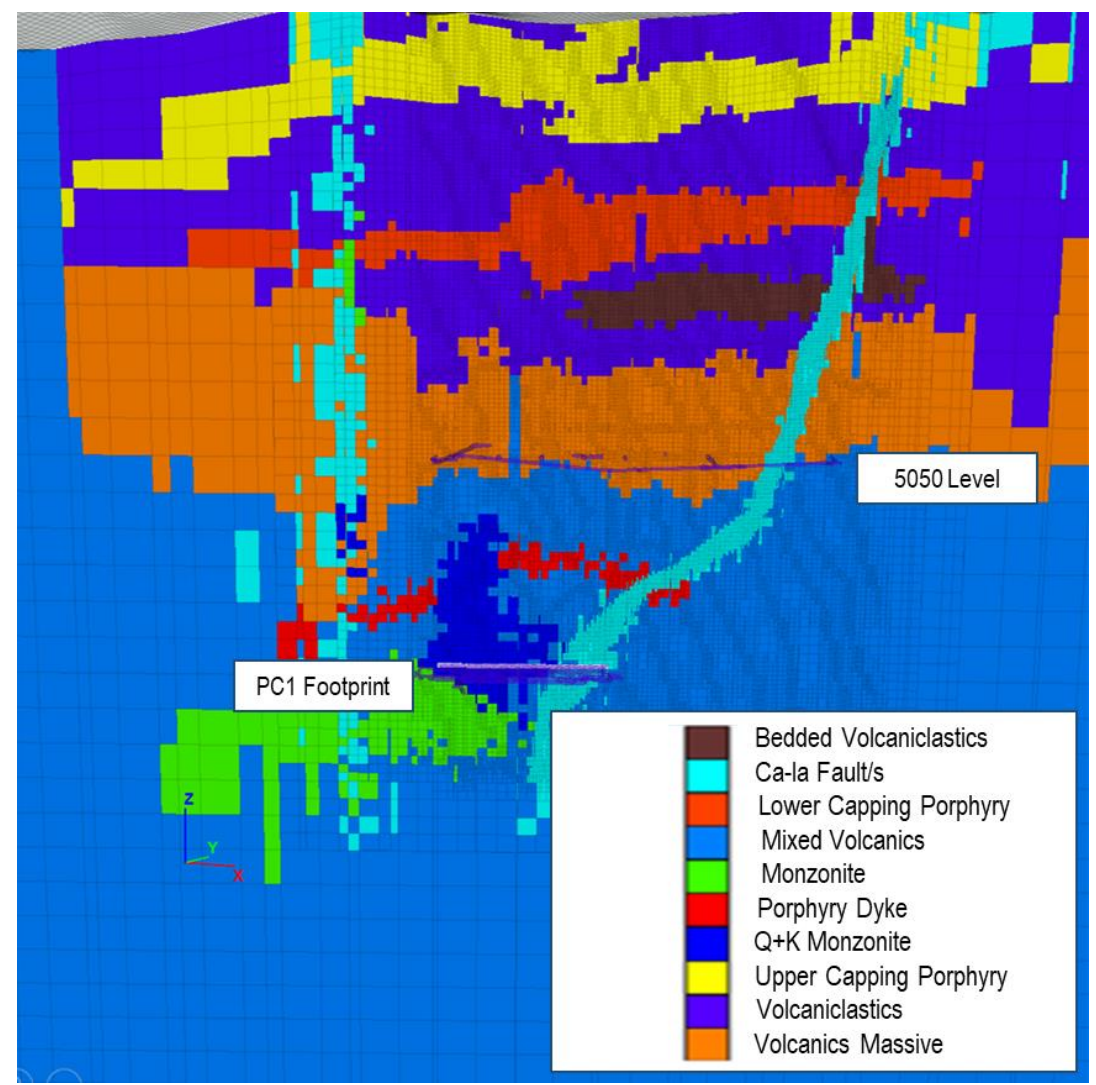

Figure 2 Geological cross-section through PC1 cave column (looking north)

A summary of the peak rock mass properties for each of the domains is provided in Table 2. A maximum $\sigma_{3}$ confinement of $15 \mathrm{MPa}$ has been used to fit the bilinear Mohr-Coulomb segments. This value has been estimated based on the expected induced stresses around the propagating cave.

Table 2 Peak rock mass strength parameters

\begin{tabular}{|c|c|c|c|c|c|c|c|c|c|c|c|}
\hline Domain & $\begin{array}{l}\text { Density } \\
\left(\mathrm{kg} / \mathrm{m}^{3}\right)\end{array}$ & GSI & $\begin{array}{l}\sigma_{c i} \\
(\mathrm{MPa})\end{array}$ & $m_{i}$ & $\begin{array}{l}E \\
\text { (GPa) }\end{array}$ & $\mathbf{v}$ & $\begin{array}{l}\text { Segmer } \\
c_{1} \\
(\mathrm{kPa})\end{array}$ & $\phi_{1}$ & $\begin{array}{l}\text { Segmer } \\
c_{2} \\
(\mathrm{kPa})\end{array}$ & $\phi_{2}$ & $\begin{array}{l}\sigma_{\mathrm{t}} \\
(\mathrm{kPa})\end{array}$ \\
\hline Upper porphyry cap & 2,780 & 67 & 147 & 15.7 & 47.7 & 0.22 & 4,252 & 54 & 9,543 & 43 & 778 \\
\hline Volcaniclastics & 2,780 & 60 & 132 & 17.2 & 26.9 & 0.23 & 2,812 & 54 & 7,945 & 41 & 376 \\
\hline Lower porphyry cap & 2,780 & 67 & 147 & 15.7 & 47.7 & 0.22 & 4,252 & 54 & 9,543 & 43 & 778 \\
\hline Bedding volcaniclastics & 2,830 & 48 & 132 & 14.5 & 17.1 & 0.25 & 1,782 & 51 & 6,108 & 37 & 181 \\
\hline Volcanic massive & 2,800 & 46 & 151 & 17.3 & 15.3 & 0.25 & 1,786 & 53 & 6,474 & 39 & 149 \\
\hline Mixed volcanic & 2,800 & 46 & 152 & 17.2 & 15.3 & 0.25 & 1,793 & 53 & 6,480 & 39 & 151 \\
\hline Monzonite & 2,800 & 59 & 157 & 26.8 & 35.0 & 0.23 & 2,869 & 59 & 9,114 & 46 & 266 \\
\hline $\mathrm{Q}+\mathrm{K}$ monzonite & 2,800 & 53 & 157 & 26.8 & 26.1 & 0.24 & 2,299 & 59 & 8,221 & 45 & 169 \\
\hline Cala Fault & 2,600 & 34 & 15 & 5.0 & 1.6 & 0.27 & 870 & 42 & 3,580 & 26 & 59 \\
\hline
\end{tabular}




\subsection{Post-peak brittleness}

The strain-softening material is described by the Mohr-Coulomb failure criteria in which the post-peak strength behaviour is a function of plastic shear strain dependent rock mass cohesion and tensile strength. Accumulated plastic shear strain (more specifically, the second invariant of the deviatoric plastic strain tensor) is a commonly used metric for irreversible shear strains in geomaterials and, in a more general sense, can be considered as a measure of damage. The plastic shear strain required in going from peak strength to a completely fragmented rock mass defined by zero cohesion (termed here the 'critical plastic strain') in the periphery of the cave defines the brittleness of the rock mass failure and can be related to GSI of the material by Equation 1.

$$
e_{p s c r i t}=12.3-\left(0.125^{*} G S I\right)
$$

The critical strain relation used is based on case histories documented in Sainsbury (2012).

The brittleness impacts both the caveability of a given unit as well as the rate at which a cave will propagate in height for a given amount of draw.

\subsection{Large-scale structure}

A ubiquitous joint model has been used to simulate the presence of large-scale fault structures. The strain softening ubiquitous joint (subiquitous) constitutive model is routinely used to represent laminated materials that exhibit non-linear material hardening or softening (Sainsbury \& Sainsbury 2017). This constitutive model is an anisotropic Mohr-Coulomb material model with ubiquitous joint properties defined by the cohesion and friction angle of the fault and orientation defined by the dip and dip direction of the fault. Ubiquitous joint properties are assigned to elements along the projected surface of the faults within the model.

The primary difference between representing faults with a ubiquitous joint model and explicit (interface) structure is that the ubiquitous joint approach simulates the effect of rock structure implicitly through material models that represent the directional and weakening effects of the fractures. The methodology, implicit or explicit, adopted to simulate planes of weakness is dependent on the spacing of the discontinuities and the amount of detail that is required in the mechanical response of the system. It has been shown by Board et al. (1996) that both the implicit and explicit techniques are able to simulate the same global rock mass response that is comparable to observed and measured behaviour in situ. However, the implicit ubiquitous joint approach is favoured due to its computational efficiency.

The numerical mesh has been refined in the region of the structures to ensure that they are modelled with a realistic width. The assignment of a dip, dip direction and radius/persistence is achieved through matching values with a triangulation of the orientated structure. Defining structures in this way allows for greater flexibility of the model and automatic updating to reflect structural model revisions.

Application of this constitutive model has shown that the assignment of ubiquitous joint orientations at the zone level results in realistic rock mass behaviour response and yields strength properties that are consistent with empirical techniques (Sainsbury et al. 2016).

Figure 3 illustrates the results of a simulated direct shear test conducted on a rock mass with a horizontal large-scale fault represented via ubiquitous joints at the large/small block interface. The fault has been simulated with a peak cohesion of $30 \mathrm{kPa}$ and friction angle of $20^{\circ}$. Complex shear softening can be simulated with the inclusion of a residual strength component to the ubiquitous joints. In this example, the cohesion is softened to $0 \mathrm{kPa}$, friction is not softened. A normal stress of $250 \mathrm{kPa}$ has been applied to the sample during test simulation. 


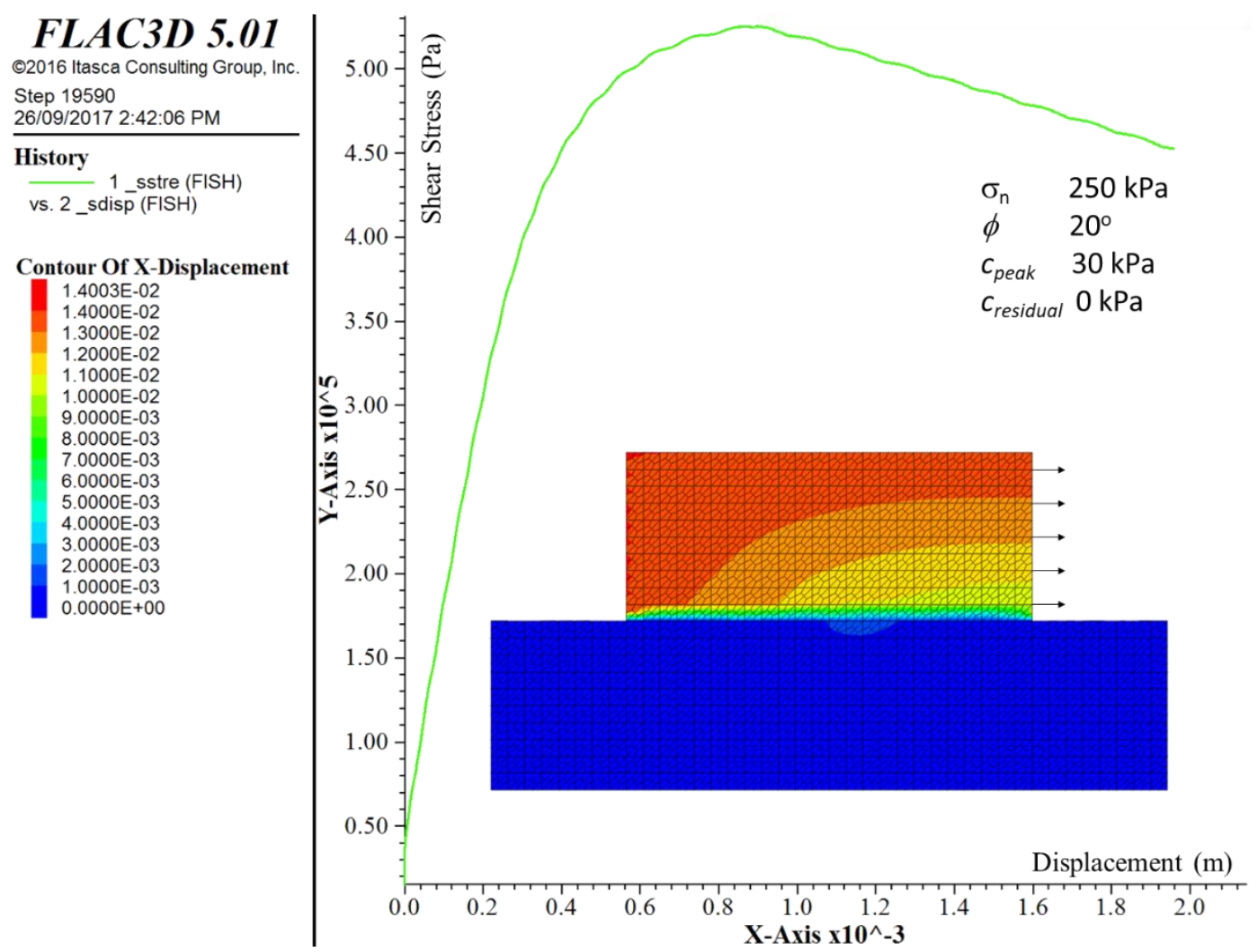

Figure 3 Simulated direct shear test. Normal stress $=250 \mathrm{kPa}$

A section through the model looking north is presented in Figure 4.

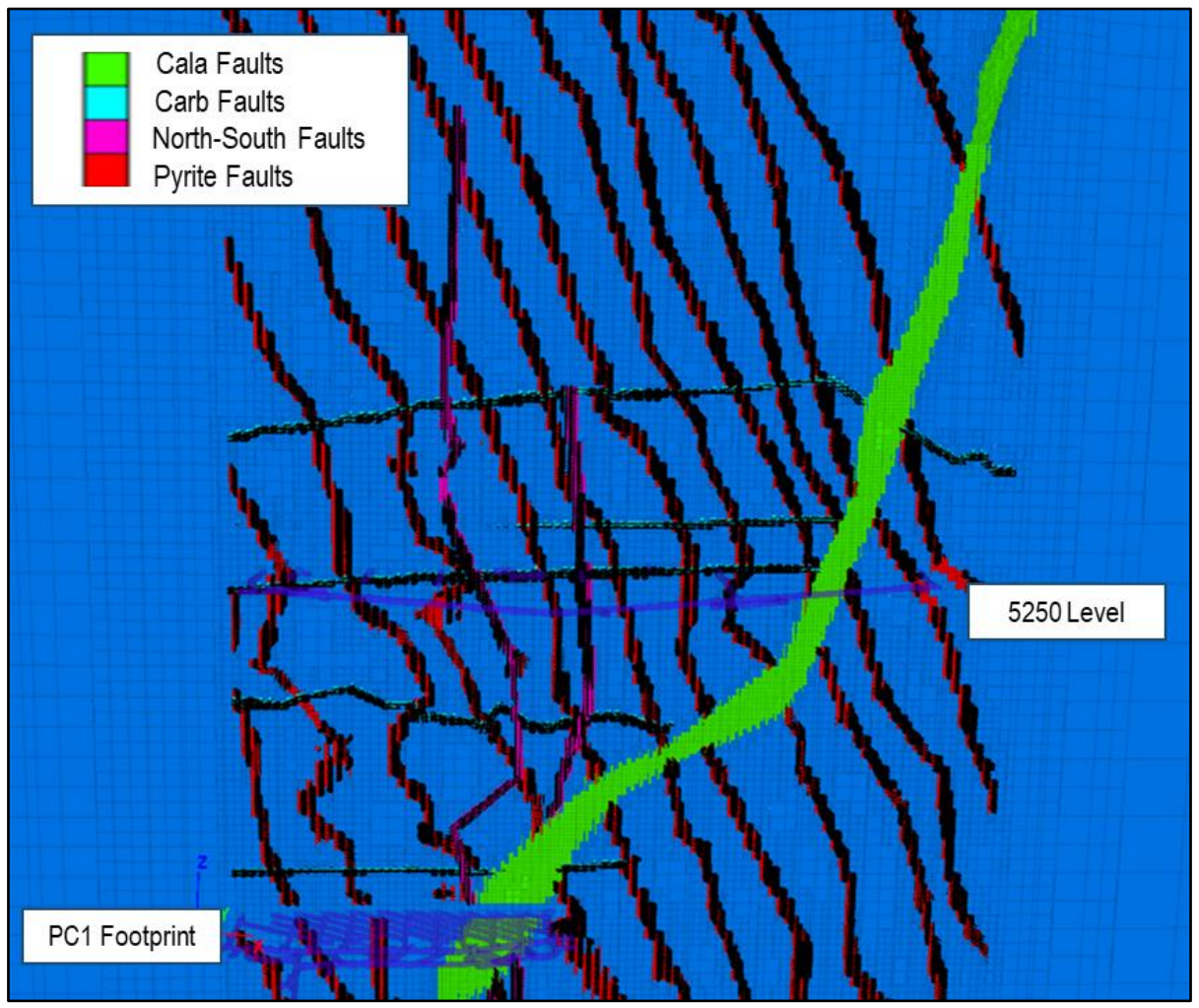

Figure 4 Structural cross-section through the numerical model (looking north) 
The Cala Fault has been represented using weak zones (matrix material) due to its significant width. Material properties assigned to this structure are presented in Table 2. The Carb, North-South and Pyrite Faults have been represented by weak oriented ubiquitous joints embedded within the rock mass matrix. The material properties assigned have been developed based on reduced values for faults and a calibration response. They are presented in Table 3.

Table 3 Geomechanical strength of ubiquitous joint structures

\begin{tabular}{|c|c|c|c|c|c|c|}
\hline \multirow[b]{2}{*}{ Structure } & \multicolumn{3}{|l|}{ Peak } & \multicolumn{2}{|c|}{ Residual } & \multirow[b]{2}{*}{ Model } \\
\hline & $\begin{array}{l}c_{1} \\
(\mathrm{kPa})\end{array}$ & $\phi_{1}$ & $\begin{array}{l}\sigma_{\mathrm{t}} \\
(\mathrm{kPa})\end{array}$ & $\begin{array}{l}c_{1} \\
\text { (kPa) }\end{array}$ & $\phi_{1}$ & \\
\hline Carb fault & 0 & 22 & 0 & 0 & 22 & Residual joint strength; not softened \\
\hline North-south fault & 0 & 25 & 0 & 0 & 25 & Residual joint strength; not softened \\
\hline Pyrite faults & 2,000 & 35 & 0 & 0 & 20 & Strain softening joint strength; perfectly brittle \\
\hline
\end{tabular}

\subsection{Preconditioning}

An initial intensive preconditioning program was an integral part of the Cadia East panel cave design with expectations that it will positively impact caveability and fragmentation. This expectation is based on empirical evidence from various Codelco mines in Chile. As a result, prior to undercutting, hydraulic fracturing (HF) was conducted over the entire PC1 undercut footprint at $2 \mathrm{~m}$ intervals from the undercut level up to the 5,050 m RL level (approximately $350 \mathrm{~m}$ height).

An additional preconditioning campaign was conducted during 2014, after the cave stalled, that affected the rock mass located in the PC1 cave column from the ground surface to the base of the capping porphyry domain.

The accurate simulation of these preconditioned volumes in the model at the correct time during production draw simulation is required to ensure the evolving stress conditions within the model reflect the in situ conditions at the time.

\subsubsection{Simulation of preconditioning}

Preconditioning research performed to date has been largely empirical in nature, without a detailed knowledge of the fundamental rock mechanics processes involved (e.g. improved caveability and fragmentation, and a reduction in seismicity).

A mine-through experiment of hydraulic fractures at the Northparkes Lift 2 Mine (Jeffrey et al. 2009) provides insight into the nature of hydraulic-induced fractures and the resulting reduction in rock mass strength and modulus. Jeffrey et al. (2009) report that the hydraulic fractures propagated through solid rock, along natural fractures and stepped along inclined shear zones.

Figure 5 illustrates an exposed hydraulic fracture crossing a shear zone on the tunnel face. The arrows indicate the trace of the fracture with green proppant contained within it. There is no clear fracture between points 1 and 2, but the fracture may have crossed this fracture at another location. Approximately $2 \mathrm{~m}$ of fracture extent is visible. 


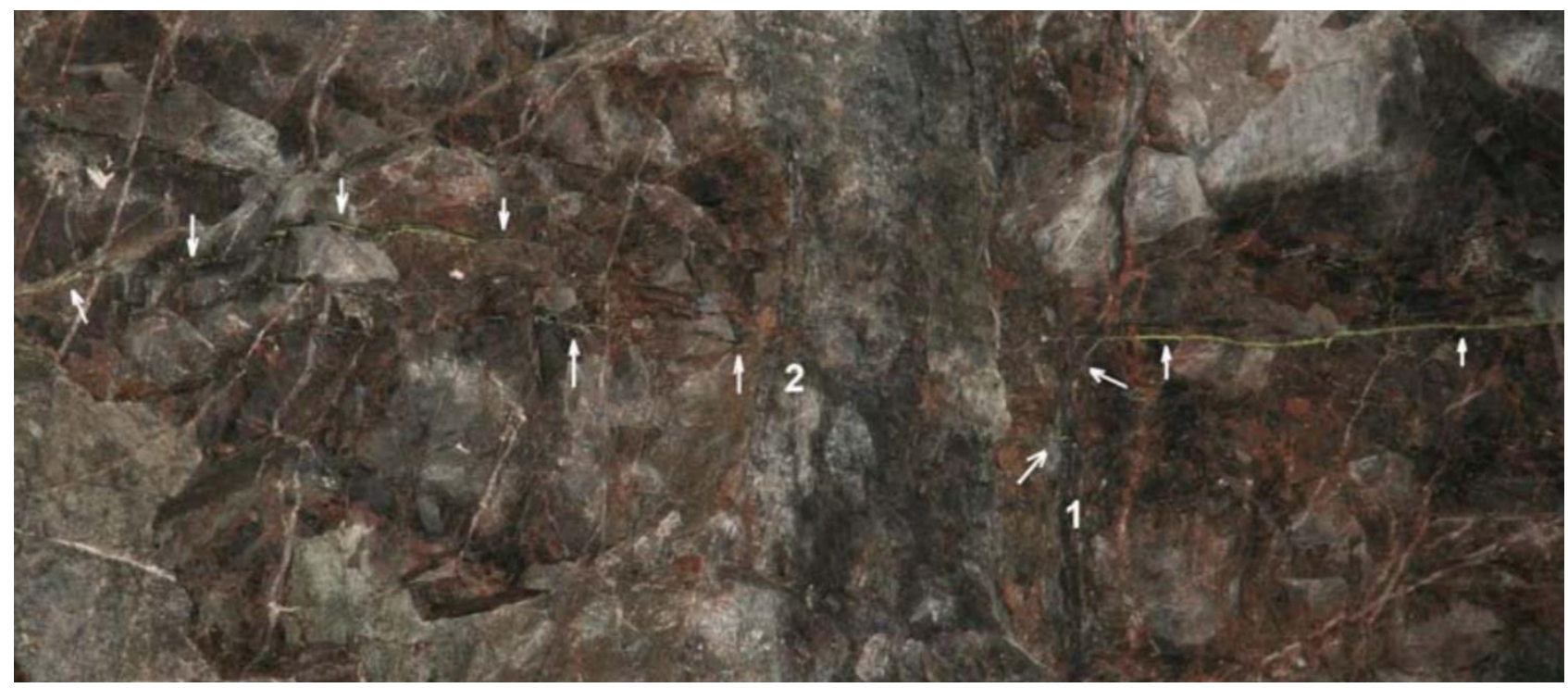

Figure 5 Hydraulic fracture (traceable via green proppant) exposed in drive (Jeffrey et al. 2009)

Based upon the mine-through experiment conducted by Jeffrey et al. (2009), the strength and modulus of the hydraulically fractured volume has been simulated by the introduction of fully persistent horizontal joints within the preconditioned volume. This has been completed through the introduction of horizontal ubiquitous joints with strength properties of cohesion $0 \mathrm{kPa}$, friction $20^{\circ}$ and tension $0 \mathrm{kPa}$. These strength assumptions are expected to represent the maximum possible rock mass strength and deformation modulus reduction caused by hydraulic fracturing.

\section{$4 \quad$ Simulation results}

Production draw has been simulated within the numerical model by applying a small downward-oriented velocity to grid points that correspond to individual drawpoint locations. The draw velocity has been scaled at a drawpoint level based on the relative tonnes extracted for the production increment (quarterly). For each mining increment, production has been controlled by mass balance calculations.

The analysis technique allows the prediction of:

- Initiation of caving.

- The shape and rate of non-uniform cave growth.

- The potential for stalling.

- Sensitivity of the predictions to input rock mass and fault parameters.

For each production increment, estimates of the mobilised and yield (aseismic) zones have been made, along with seismicity and air gap potential. The results of the mobilised and yield zones are presented in Figures 6 , 7 and 8.

Figure 6 presents the mobilised (yellow) and yield/aseismic (blue) limits within the model as they evolved during 2013. 

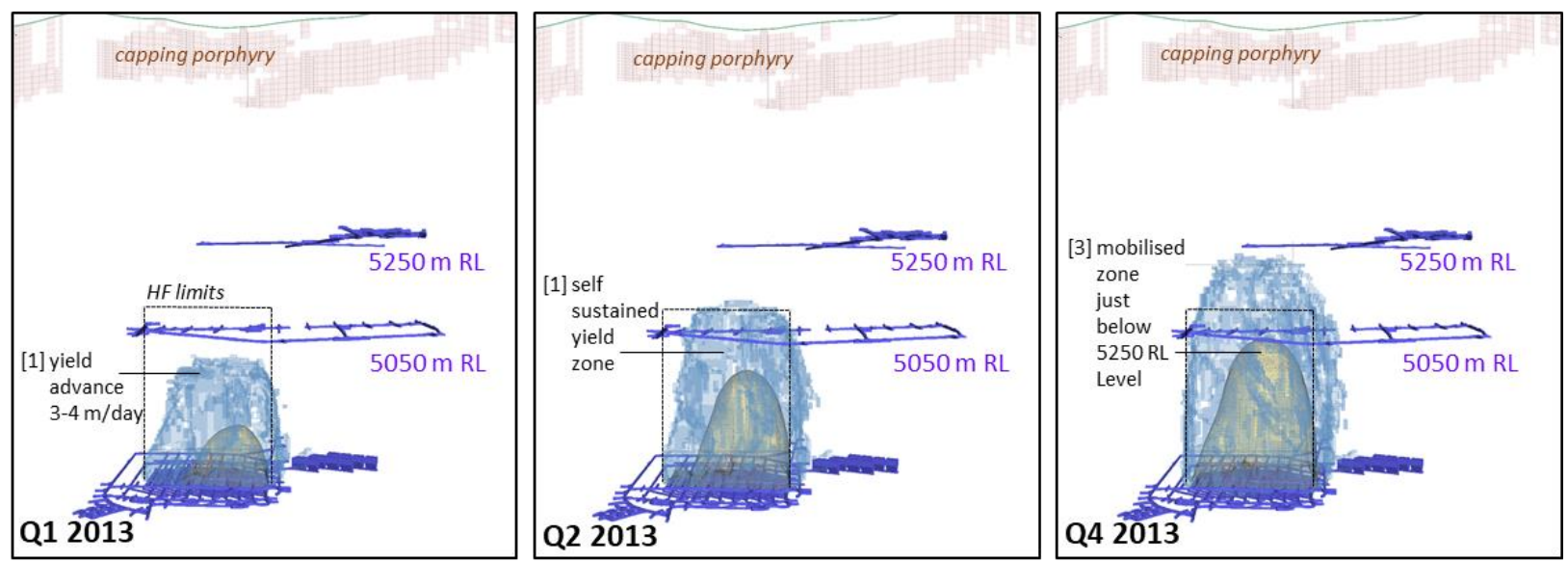

Figure 6 Simulated cave propagation behaviour (2013)
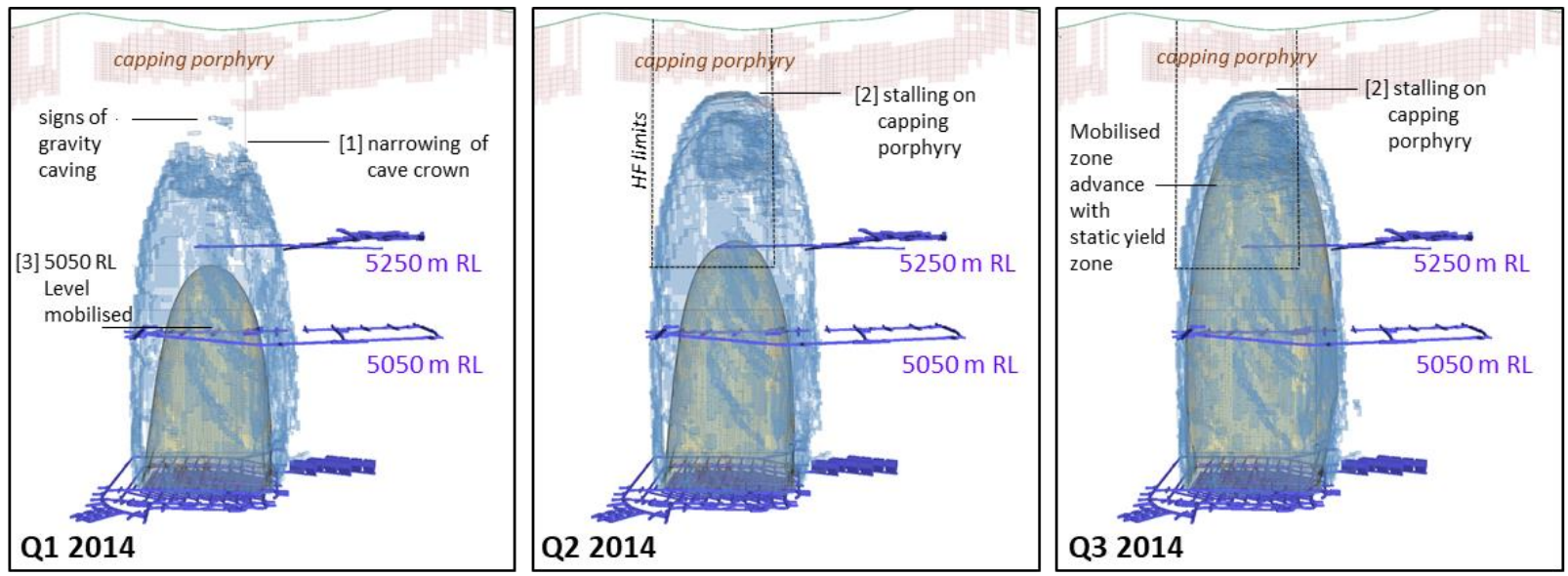

Figure 7 Simulated cave propagation behaviour (2014)
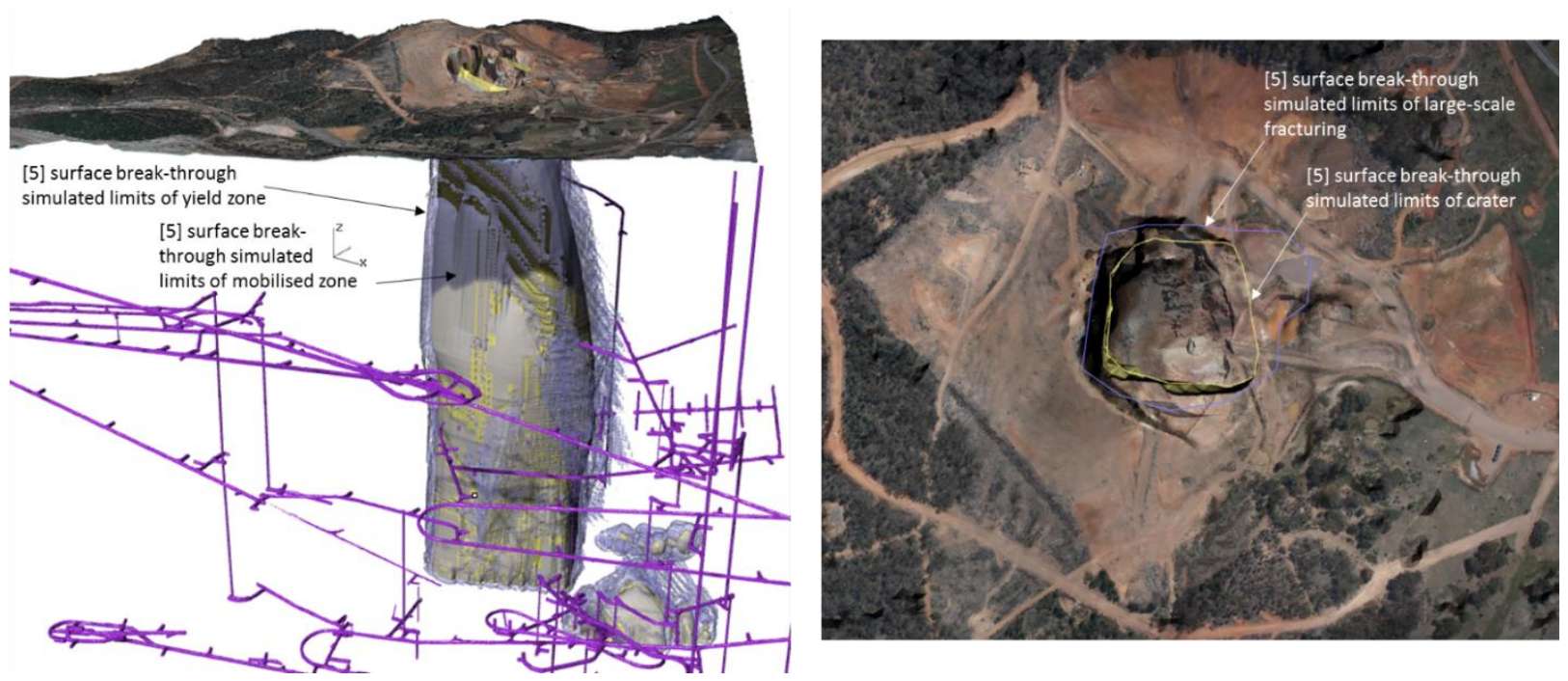

Figure 8 Simulated subsidence behaviour (2014)

During this period, the cave reached a critical hydraulic radius and propagated to just below the 5,250 $\mathrm{m} \mathrm{RL}$ Level. Propagation rates of $3-4.5 \mathrm{~m} /$ day are observed through the preconditioned (HF limits) volume. Based on an average solid rock height of draw of $24 \mathrm{~m}$ (maximum $58 \mathrm{~m}$, minimum $1 \mathrm{~m}$ ), this equates to a propagation rate in excess of 10:1. Based on historical data (presented in Table 4) this rate is consistent for a deep and high stress block/panel cave. 
Table 4 Yield zone propagation rates measured as ratio of yield zone height to solid rock height of draw (after Sainsbury 2010)

\begin{tabular}{llll}
\hline Operation & Method & Propagation rate & Reference \\
\hline El Teniente, Chile & Panel & $5: 1$ & Villegas (2008) \\
Henderson Mine, Colorado, USA & Panel & $7: 1$ & Board et al. (2009) \\
Henderson Mine, Colorado, USA & Panel & $8.2: 1$ & Sainsbury et al. (2005) \\
Australian Coal Mine & Longwall & $8.9: 1$ & Hebblewhite (1995) \\
DOZ Mine, Indonesia & Block & $6-10: 1$ & Szwedzicki et al. (2006) \\
Kimberley Mines, South Africa & Block & $6-12: 1$ & Guest (2009) \\
Lakeshore Mine, Arizona, USA & Block & $10: 1$ & Panek (1984) \\
Questa Mine, New Mexico, USA & Block & $10: 1$ & Gilbride et al. (2005) \\
San Manuel Mine, Arizona, USA & Panel & $10: 1$ & Gilbride et al. (2005) \\
Athens Mine, Michigan, USA & Block & $14: 1$ & Boyum (1961) \\
Palabora Mine, South Africa & Block & $15: 1$ & Sainsbury et al. (2008) \\
Palabora Mine, South Africa & Block & $20: 1$ & Pierce et al. (2006) \\
Chinese Coal Mine & Longwall & $31.3: 1$ & Liu (1981) \\
\hline
\end{tabular}

Figure 7 presents the mobilised (yellow) and yield/aseismic (blue) limits within the model as they evolved during 2014. During this period, the cave yield stalled on the upper capping porphyry domain. An extensive $\mathrm{HF}$ program was completed during Q2 and Q3. Continued production draw is seen through the propagation of the mobilised zone up through the 5,050 and 5,250 $\mathrm{m}$ RL Levels in accordance with in situ observations. However, the yield zone is stagnant. This suggests the development of an air gap within the model.

Figure 8 presents the mobilised/crater (yellow) and yield/aseismic (blue) limits within the model as they evolved rapidly at the end (during Q4) of 2014 and broke through to the ground surface. There was minimal seismic activity observed within the crown of the cave immediately prior to and during the rapid cave propagation. As a result of this, it can be concluded that the hydraulic fracturing campaign directly influenced the cave propagation behaviour, allowing the introduced fractures to assist in a gravity caving mechanism through the capping porphyry. As the cave advanced through this preconditioned domain and intersected the weathered surface rock mass, rapid longwall propagation to surface occurred. The gravity failure mechanism through and above the capping porphyry is also confirmed through an assessment of the yielded rock mass zone above the porphyry, which is quite tight compared to below the porphyry.

The shape of the crater at breakthrough is observed to be influenced by the structural model. The crater shows to be bounded by fault structure observed as the sub-vertical structures daylighting in the face. The crater simulated at the end of 2014 in the model is coincident with in situ observations at that time. This result suggests that the methodology used to simulate the large-scale structures and preconditioning described herein is valid for this case study.

The calibration of the mobilised zone/crater development within the model suggests a displacement of $10 \mathrm{~m}$ is coincident with this region based on in situ observations. Observations 3 and 5 in the background (Section 1) have been used to calibrate this response in the model.

Calibration of the yield zone has been completed with a maximum principal strain of $5 \%$. 


\section{Conclusion}

Back-analysis of cave propagation of PC1 has been conducted to confirm design parameters for the optimisation of future draw strategies. The modelling results are consistent with the monitored and observed propagation rate and shape in situ. The successful calibration provides confidence in the methodology used to represent preconditioning and the large-scale structures. These methodologies allow large-scale life-of-mine modelling to be conducted without sub-modelling techniques required to be used.

\section{Acknowledgement}

The authors acknowledge the permission of Newcrest to publish and present this paper.

\section{References}

Board, M, Chacon, E, Varona, P \& Lorig, L 1996, 'Comparative analysis of toppling behaviour at Chuquicamata open pit mine, Chile', Transactions Institute of Mining and Metallurgy, Section A, vol. 105, A11-A21.

Cavieres, P, Gaete, S, Lorig, L \& Gómez, P 2003, 'Three-dimensional analysis of fracturing limits induced by large scale underground mining at El Teniente mine', in P Culligan, HH Einstein and AJ Whittle (eds), Proceedings of the 39th U.S. Rock Mechanics Symposium (Soil and Rock America 2003), Verlag Glückauf, Essen, pp. 893-900.

Jeffrey, RG, Bunger, A, LeCampion, B, Zhang, X, Chen, Z, van As, A, ... Mainguy, M 2009, 'Measuring hydraulic fracture growth in naturally fractured rock', Proceedings of the 2009 SPE Annual Technical Conference and Exhibition, Society of Petroleum Engineers, Richardson, https://dx.doi.org/10.2118/124919-MS

Laubscher, DH, 1994, 'Cave mining - the state of the art', Journal of the South African Institute of Mining and Metallurgy, vol. 94, no. 10, pp. 279-293.

Lee, M 2012, Cadia East - Review of Rock Stress Measurements, AMC Consultants Pty Ltd report 111153: February 2012 to Newcrest Mining Limited, AMC Consultants Pty Ltd.

Lupo, JF 1998 'Large-scale surface disturbances resulting from underground mass mining', International Journal Rock Mechanics and Mining Science, vol. 35, no. 4-5, paper no. 25.

Pierce, M, Cundall, P, Mas Ivars, D, Darcel, C, Young, RP, Reyes-Montes, J \& Pettitt, W 2006, Mass Mining Technology Project: Six Monthly Technical Report, Caving Mechanics, Sub-Project No. 4.2: Research and Methodology Improvement, and Sub-Project 4.3, Case Study Application, ICG06-2292-1-Tasks 2-3-14, Itasca Consulting Group Inc.

Pierce, M, Cundall, P, Potyondy, D \& Mas Ivars, D 2007, 'A synthetic rock mass model for jointed rock', in E Eberhardt, D Stead \& TMorrison (eds), Proceedings of the 1st Canada-US Rock Mechanics Symposium, Rock Mechanics: Meeting Society's Challenges and Demands, vol. 1, American Rock Mechanics Association, Alexandria, pp. 341-349.

Sainsbury, D \& Lorig, L 2005, Caving Induced Subsidence at the Abandoned Grace Mine, confidential Itasca Consulting Group report to Arcadia Land Company.

Sainsbury, B, Pierce, M \& Mas Ivars, D 2008, 'Analysis of caving behaviour using a synthetic rock mass - ubiquitous joint rock mass modelling technique', in Y Potvin, J Carter, A Dyskin \& R Jeffrey (eds), Proceedings of the 1st Southern Hemisphere International Rock Mechanics Symposium, vol. 1, Australian Centre for Geomechanics, Perth, pp. 243-253.

Sainsbury, B 2010, 'Sensitivities in the numerical assessment of cave propagation', in Y Potvin (ed.), Proceedings of The Second International Symposium on Block and Sub-level Caving, Australian Centre for Geomechanics, Perth, pp. 523-535.

Sainsbury, D, Lorig, L \& Sainsbury, B 2010, 'Investigation of caving induced subsidence at the abandoned Grace Mine', in Y Potvin (ed.), Proceedings of the Second International Symposium on Block and Sub-level Caving, Australian Centre for Geomechanics, Perth, pp. 189-204.

Sainsbury, D, Sainsbury, B, Board, M \& Loring, D 2011, 'Numerical back analysis of structurally controlled cave initiation at propagation at the Henderson Mine', in AT Innacchione, GS Esterhuizen \& AN Tutuncu (eds), Proceedings of the 45th US Rock Mechanics/Geomechanics Symposium, American Rock Mechanics Association, Alexandria.

Sainsbury, B 2012, A Model for Cave Propagation and Subsidence Assessment in Jointed Rock Masses, PhD thesis, University of New South Wales, Kensington.

Sainsbury, B \& Stöckel, B-M, 2012, 'Large-scale caving and subsidence assessment at the Kiirunavaara Lake Orebody', Proceedings of MassMin 2012, Canadian Institute of Mining, Metallurgy and Petroleum, Westmount.

Sainsbury, D, Sainsbury, B, Paetzold H-D, Lourens, P \& Vakili, A 2016, 'Cave propagation and subsidence behaviour of Lift 1 at the Palabora block cave mine', Proceedings of MassMin 2016, The Australasian Institute of Mining and Metallurgy, Melbourne.

Sainsbury, B \& Sainsbury, D 2017, 'Practical use of the ubiquitous-joint constitutive model for the simulation of anisotropic rock masses', Rock Mechanics and Rock Engineering, vol. 50, no. 6, pp. 1507-1528, http://dx.doi.org/10.1007/s00603-017-1177-3

van As, A, Davison, J \& Moss, I 2003, Subsidence Definitions for Block Caving Mines, Rio Tinto Technical report, 59 p. 

at the Cadia East mine 